\title{
Spatial Analyses of Social Policies and of a Social Safety Net
}

by Vicky $\mathrm{N}$ Albert ${ }^{1 *}$. Jaewon Lim $^{2}$

1. School of Social Work, University of Nevada Las Vegas, 4505 S. Maryland Pkwy, Box 455032, Las Vegas NV, 89154

2. School of Public Policy and Leadership, University of Nevada, Las Vegas, 4505 S. Maryland Pkwy, Box 454030, Las Vegas NV, 89154

*Author to whom correspondence should be addressed:Vicky.Albert@unlv.edu

\begin{abstract}
During the 2008 Great Recession, many families with children relied on cash assistance from Temporary Assistance for Needy Families (TANF) program. The present study applied Exploratory Spatial Data Analysis (ESDA) tools to analyze geographically varying spatial clusters of states' unemployment rates, TANF caseload growth rates, TANF policy choices such as benefit levels and TANF responsiveness rates to the recession. We analyzed 45 contiguous states and Washington D.C. A standardized TANF responsiveness index was developed to compare states' TANF growth rates relative to their labor market conditions. The western states were found to be very responsive to the recession with ratios greater than one. In contrast, Texas and Arizona, with ratios below 1, were unresponsive to the recession. The presence of strong spatial clusters in unemployment rate and TANF maximum aid were found. In the case of maximum aid, there was a strong presence of Low-Low spatial clusters in Southern States and High-High clusters in Northeastern States. The findings suggest that several neighboring states in the northeast and some in the south had similar levels of financial commitment during the 2008 recessionary as the ones found by earlier research conducted during non-recessionary periods. The findings have implications for future federal actions and for state level collaboration.
\end{abstract}

Keywords: Exploratory Spatial Data Analysis; LISA; Temporary Assistance for Needy Families (TANF); TANF responsiveness to Great Recession; Spatial Clusters; TANF policy choices; TANF maximum aid 


\section{Introduction}

Spatial analysis is widely used in the field of regional science, sometimes for the purpose of informing national public policy makers about the heterogeneity in social conditions among states or regions. The field of regional science concerns itself with addressing problems and issues measured at specific geographic levels, such as urban, rural, or regional. For example, a regional scientist may analyze migration patterns or linkages between economic and social conditions shared by multiple regions or geographic units [1,2].

Unlike in the field of regional science, spatial analysis is rarely applied for examining social policies or social programs. Yet, like regional science, the findings of spatial analyses applied to social policy and social programs can be quite valuable since they allow academics and policy makers to identify the extent to which neighboring states share selected economic or social problems, especially during the major economic downturns. By identifying and monitoring spatial patterns, we can maximize such highly needed information by academics and policy makers alike [2]. With such knowledge in hand, extra federal allocations can be better targeted to specific needy geographic areas during recessions. Without good information sharing about the states' economic and social conditions during economic downturns, it is difficult for stakeholders to target their resources in the most efficient manner. In the absence of good knowledge based on spatial analyses, it is also difficult for neighboring states to collaborate and to properly service those in need.

The present study applies spatial analyses to examining social policies and a social safety net during the Great Recession. The Great Recession that officially began in December 2007 and ended in June 2009 was the most severe recession since the Great Depression of the 1930s. Because of this major economic downturn, millions of Americans relied on a number of safety 
nets designed to provide them with cash and other benefits. One of the safety nets that some poor families relied on was Temporary Assistance for Needy Families Program (TANF), commonly referred to as welfare. This program, as well as its predecessor Aid to Families with Dependent Children (AFDC), provides cash assistance to needy families with dependent children and frequently connects them to other services or benefits such as Supplemental Nutrition Assistance Program (SNAP), previously referred to as food stamps [3].

Many economists argue that the official national recession lasted from 2007 to 2009. However, a closer examination of the rising unemployment rate in each of the 50 states and D.C. by several earlier studies reveals that the nation experienced 51 different recessions [3-5]. In most states, the unemployment rate began rising before the onset of the national recession in 2007 and it kept increasing in many states until 2011. Moreover, the increase in the TANF rolls was greater when examined during the unique period of rising unemployment in each state and D.C. rather than during the dates of the official recession 2007 to 2009 recessions [3-5].

While their unemployment rates and TANF growth rates varied substantially across the nation, states' policy choices for TANF varied as well. Some states made their programs very unattractive during their recession. For example, while its unemployment rate was rising by over $200 \%$ during its recession, Arizona substantially lowered the nominal value of its TANF maximum aid (maximum benefits for families with no other income) during the recession in order to cut costs. Many other states just let the values of maximum aid erode with inflation [3$5]$.

In contrast to most related studies, the present study analyzes the 2008 recession in each state and develops an index of TANF responsiveness to the recession that accounts for each state's 
labor market performance. This unique index provides an accurate picture of rising TANF caseloads in response to each state's labor market performance.

We apply an Exploratory Spatial Data Analysis (ESDA) method which is a geographic or spatial approach to analyzing similarities or differences between neighboring states and regions with regards to their economic dimensions, TANF responsiveness index score and TANF policies. Earlier research shows that these dimensions are good predictors of TANF enrollment [4]. To our knowledge, earlier research did not analyze the spatial nature of these selected dimensions during the 2008 recession.

Prior to applying spatial analytic approach, we review existing evidence about states' economic conditions and TANF responsiveness to the 2008 recession.

\section{Background}

The research reviewed here analyzed TANF response to the Great Recession or state-level TANF policy choices that affected TANF enrollment during the Great Recession. To our knowledge, there is no earlier research that examined the geographic nature of states' economies, TANF policies or TANF responsiveness during the 2008 recession of each state.

\subsection{TANF Response to Great Recession}

Most previous analyses of safety nets response to the Great Recession concluded that in comparison to safety nets such as SNAP or Unemployment Insurance, TANF grew quite modestly during the official dates of the Great Recession [6-8]. A basic method that many of these analysts used to examine the response of TANF to the Great Recession was to compute the 
rise in the national TANF caseload during the dates of the national official recession, December 2007 to June 2009. This method yielded an overall rise of 6.8 percent in the TANF caseload [3]. More recent research found that rising state-level unemployment rates and TANF increases yielded different results than ones found with national-level analysis. Earlier research found that the unemployment rates began rising in 36 states before the onset of the national recession in December 2007. The unemployment rate increased in every state from 2006 to 2011, although in some states the unemployment rate reached its peak and started to fall before that end date [3-5]. The state with the lowest increase in its unemployment rate was Alaska with a $39 \%$ rise; the state with the highest increase was Utah with a $246 \%$ rise. The average increase was $133 \%$, with 36 states experiencing increases of greater than 100 percent [3].

Earlier studies, whether conducted on a national or state level, captured the increases in TANF caseloads without simultaneously capturing the relative growth in unemployment rate in the state or nation. Clearly, when unemployment rate increases are small relatively to national level increases, it would be expected that TANF enrollment would be small in response. Thus, on a state-level, the responsiveness of TANF to the Great Recession is best understood when TANF growth rate during a state recession is calculated relative to the average national growth of TANF caseloads as well as the states' growth of unemployment relative to national unemployment growth. With such calculations in hand is it possible to accurately make comparisons between TANF responsiveness to the recession and to discern spatial patterns. The present study develops an index that captures such responsiveness, one that was not found in earlier studies. 


\subsection{TANF Policy Choices: Earlier Findings}

Some researchers argue that the modest increase of 6.8 percent of the national TANF caseload during the Great Recession is primarily due to strict welfare reform policies that have existed since 1996 [6]. While this argument was presented or implied in most earlier studies, these studies did not provide evidence that welfare reform policies, implemented in 1996, effected TANF enrollment rates during the recession of 2008. It is reasonable to suspect that selected TANF policies had some impact on TANF enrollment as evidenced by one study [4]. Since 1996, with the passage of welfare reform legislation, the number of families on the TANF caseload had declined substantially, from about 4.8 million families in 1995 to about 1.6 million families at the beginning of the official Great Recession of 2008 [3]. The share of the poor who received cash welfare (TANF) after 1996 has dropped substantially.

Since 1996, federal life time limits require that TANF recipients no longer receive cash assistance from federal monies during their lifetime, after receiving benefits for at most 60 months. In addition to lifetime limits, federal work requirements mandate that participants engage in work-related activities for at least 30 hours per week (some exemptions are allowed). States can impose shorter life time limits or greater work requirements. If TANF participants do not comply with federal or state requirements, states impose sanctions which also vary in their severity from state-to-state [4].

Research investigating the extent to which welfare policy choices affected TANF enrollment during the 2008 recession is in short supply. On a national level, one study evaluated the impact of several 1996 policies such as time limits, stringent work requirements and sanctions on enrollment of families with children in TANF program during the Great Recession [9]. Using aggregate national time series administrative AFDC/TANF caseload data from 1980 through 
2009 as well as the presence of TANF policies such time limits, stringent work requirements and sanctions as independent (explanatory) variables, their findings suggest that in the absence of time limits, stringent work requirements and sanctions, the TANF caseload would have increased more than it did than in the presence of such provisions [9]. This study provided an excellent empirical evidence of how the national TANF caseload responds to strict national policies. It did not, however, consider the state-to-state impact of policy variations on TANF enrollment and the individual state's recession.

A more recent study considered state-to-state variations in policies and economies and how these shaped enrollments during the 2008 recession [4]. The study found that that all else constant, TANF did not grow as much as it would have in the 2008 recession partially due to shorter lifetime limits (less than 60 months) or temporary time limits, multiple severe policies, or TANF benefit cuts in some states during the recession [4].

None of the above studies examined the geographic nature of states' economies, TANF policies or TANF responsiveness during the 2008 recession. Dating back to early 2000s, however, one study conducted used spatial, temporal, and spatial-temporal approaches in order to explore the extent to which states and their neighbors changed their TANF cash benefit levels relative to their neighbors [10]. Using a tree-based regression approach, the country was divided into regions where benefit levels are relatively homogeneous within each region yet quite different between the regions. The findings suggested that both high and low benefit states paid attention to the generosity in benefit levels of their neighbors [10].

Taken together, studies exploring geographic patterns of TANF policies or TANF responsiveness to the economy during recessions are in short supply. The present study examines the geography of these variables during the recession of each state. 


\section{The Study: Purpose, Questions and Sample}

The primary purpose of this study is to gain an in-depth understanding of spatial distribution patterns of the economies, TANF policy choices such as benefit or payment levels and TANF responsiveness to the recession in the contiguous states and D.C. during each of their 2008 recessions. We selected to apply spatial analyses to these variables because they were found to be good predictors of TANF enrollment in earlier research.

In turn, we ask the following research questions. First, how did unemployment rate and TANF growth rate vary across states during their own 2008 recessions? Second, how did selected TANF policy choices such as benefit levels or sanctions vary across states when TANF was at its peak in each state around the 2008 recession? Third, how responsive was TANF to the 2008 recession in each state? To answer this question, we developed an index that allowed us to compare TANF responsiveness in states with different labor market performance.

We used an Exploratory Spatial Data Analysis (ESDA) tool in order to identify and statistically test the presence of spatial clusters and/or outliers as defined and explained in subsequent discussion. Some of the questions asked when using the tool were whether there were any spatial association of unemployment growth, TANF growth at state level during the Great Recession as well as for TANF responsiveness? Next, was there a spatial association of TANF maximum aid (payment levels) or other policy choices during the Great Recession? We ask whether the presence of global spatial autocorrelation and local autocorrelation exists as well as test its statistical significance prevails with each dimension. We applied the Moran I statistics to test global spatial autocorrelation and LISA to test the presence of any spatial associations at local level. 
We analyzed all contiguous jurisdictions including D.C. when mapping unemployment rate. Throughout the study we use the U.S. Census definitions of Regions ${ }^{1}$. Of 13 states in the West Region, Alaska and Hawaii are dropped from the analyses because these are not contiguous to other states in the present study. The 11 West Region states, excluding Alaska and Hawaii experienced a more severe recession than their counterparts in other regions. As further explained in the paper, we also excluded four states when analyzing TANF because these states witnessed a decrease in their TANF enrollment while their unemployment rate was increasing. These states are Georgia (GA), Indiana (IN), North Dakota (ND) and Rhode Island (RI). The downward trend in their TANF enrollment existed prior to the recession in these states. These states were left out of our TANF analyses. The observation period for the present study was from January 2005 until December 2013.

\section{Data and Variable Calculations}

The study uses multiple methods in order to understand spatial patterns and associations of regional and states' social policies and of TANF cash assistance program's responsiveness during the states' recessions. Prior to applying an exploratory spatial method, we calculated the unemployment growth rate, TANF growth rate and TANF benefit levels during each state's recession as discussed below.

\subsection{The Unemployment Growth Rate}

The unemployment rate is an important indicator of a state's economic health, but it is not

\footnotetext{
${ }^{1}$ We present census data for various programs, US Census groups 50 US states and the District of Columbia into four census regions - West, Midwest, South and Northeast. Each census region is composed of multiple census divisions and there are total of nine census divisions. For further information, refer to the following link, https://www2.census.gov/geo/pdfs/maps-data/maps/reference/us_regdiv.pdf
} 
the sole indicator of a recession. We utilized unemployment rate data from the Bureau of Labor Statistics (BLS) from January 2005 to December 2013.

We calculated increases in seasonally adjusted unemployment rate in each jurisdiction from the unemployment base month to its peak in order to identify varying recessionary periods. Unemployment rate base month is the month of minimum unemployment rate before unemployment began to rise to its peak around Great Recession. Unemployment rate peak month is the month of maximum unemployment rate that occurred between December 2006 and December 2013. Some examples of the dates of peak unemployment rates are Alabama 12/09; Alaska, 12/10; Arizona, 03/10; California, 10/10; Colorado, 11/10. The labor market condition data during these peaks were retrieved from Department of Labor Statistics. Bureau of Labor Statistics, Local Area Unemployment, "Statewide Unemployment Rate, Seasonally Adjusted" (http://www.bls.gov/lau). According to our calculations, the unemployment rate began rising in 35 contiguous states prior to December 2007, the onset of the national recession. In five of those states, unemployment rate started to increase almost a year before the official beginning of Great Recession in the U.S. The unemployment rate continued to increase in 48 contiguous jurisdictions after the national recession ended in 2009.

The western region clearly experienced a larger increase in its unemployment rate than other regions. Among the 11 contiguous states in the West Region, 9 states had an above national average rise in unemployment rate. The two states in the West Region that had below average rise in unemployment rate were New Mexico (NM) and Washington (WA). 


\subsection{TANF Caseload Growth Rate}

States with larger increases in their unemployment rates during the recession would be expected to have relatively larger increases in their TANF caseloads in response. To be consistent with the seasonally adjusted measure of unemployment rate, we applied a 12-month moving average to smooth out the seasonality of the TANF caseload growth rate.

Our calculations reveal that, with the exception of four states, all contiguous states and D.C. had increases in their TANF caseloads during the recession. The four states with the decreases in TANF caseloads during their own recession were Georgia, Indiana, North Dakota and Rhode Island and this pattern prevailed prior to the recession in these states. These states were left out of our analyses.

As expected, many of the states that experienced relatively larger increases in their unemployment rates also experienced relatively larger increases in their TANF caseloads. Utah and Nevada had the greatest increases in their unemployment rates and also experienced above average increases in their TANF caseloads. Two states in the western region (AZ and MT) experienced above average increases in their unemployment rates but below average increases in their TANF caseloads. The majority of states in non-west region (20 out of 34 states) had below average increases in the unemployment rates as well as in their TANF caseloads.

The Center on Budget and Policy Priorities (CBPP) provided us with TANF caseload data for each state. The center received TANF data directly from each state. With the TANF data in hand, we calculated the peak date of TANF caseload in each state after TANF started to grow following the substantial growth in the unemployment rate. The dates for TANF peak varied from state-tostate. Some examples of the dates of TANF peaks are Alabama 12/10; Alaska 08/11; Arizona, 12/09; Arkansas, 12/11; California, 06/11. 


\subsection{Policy Choices: TANF Maximum Aid and Other TANF Policies}

We selected TANF maximum Aid for a family of three with no income because this variable has repeatedly shown to be a good predictor of TANF enrollment [4]. We took the value of at TANF maximum aid at the peak month of TANF caseload, which varied from state to state. Total TANF maximum aid for a family of three was deflated by the CPI (Consumer Price Index) provided by Bureau of Labor Statistics (BLS) and recalculated in constant 2007 U.S. dollar terms. Cash assistance benefit levels were provided by US Department of Health and Human Services, Administration for Children and Families (http://anfdata.urban.org/wrd/databook.cfm).

Initially, we included in our spatial analyses several policy variables aside from maximum aid. These variables' source was the Urban Institute welfare rules data book for several years around the 2008 Great Recession. There were different authors for each of the years used. For an example, see source for 2010 [11]. We coded each of the policy choices as dummy variables $(1=$ present and $0=$ absent $)$. We coded the policy choice at the date of TANF caseload peak. Each policy choice (e.g. severe life time limits) was coded as 1 when it was present and 0 when it was absent.

We started by selecting an important policy choice entitled "Severe life time limits or temporary time limits". The federal time limits on TANF cash assistance is 60 months with some exceptions allowed. States, however, can shorten this time limit to less than 60 months and in such a case we consider the state's time limit policy to be severe. If the state has temporary time limits in addition to lifetime limits, a code equal to 1 also was assigned, otherwise zero was assigned. Temporary time limits may mean that families are required to "sit out" for a period of time and do not receive cash assistance during such period of time. The families are allowed to return after their sit out period is over. Nevada is a state with such time limits. The second policy choice was 
"Severe Work Requirements". The federal requirements are that, with some exceptions, heads of household in the TANF program engage in work related activities (e.g.: on job training or paid job) for a maximum 35 hours per week. We assigned a code of 1 when work-related activity requirement for single head of household is greater than or equal to 35 hours per week, zero otherwise. The next policy variable is "Severe Sanctions". This variable varied substantially from state-to-state at TANF caseload peak. We examined the maximum severe sanction (not initial) for noncompliance with work requirements for single-parent head of unit at the time that TANF caseload peaked. We assigned a 1 when a state cuts an entire family's benefits in response to a violation or when a case is closed for a maximum sanction of 6 months or longer and family had to reapply for TANF.

Two policies intended to encourage self-sufficiency at the point of application are diversion policies and job search. As of July 2010, for example, more than two out of three states provided formal diversion policies. Under this policy, families may choose to receive a lump-sum cash payment to deal with their immediate needs instead of receiving a monthly TANF cash assistance [11]. If families accept the diversion payments, then they may not apply for monthly TANF benefits for a period that varies from state-to-state. Some states require that applicants participate in diversion programs and job search prior to applying for longer-term benefits. In 2010, as a condition of eligibility, almost half the states required that applicants participate in job search at time of application [11]. When states had diversion payments or mandatory job search at entry, a code of 1 was assigned and zero otherwise.

Table 1 shows which states had severe policies at their TANF caseload peak during the state's 2008 recession. Of the contiguous western states, California, Idaho and Nevada had two severe policies at their TANF's caseload peak month during their 2008 recession. Yet, despite 
the presence of these policies, the three states' TANF caseloads grew substantially during the recession. The remainder the of the western contiguous states did not have more than one severe policy. Interestingly, in Table 1, there are no severe policies in place at Arizona's TANF peak. However, it should be noted that since Arizona's TANF peak in December of 2009, the state became more restrictive over time, implementing more severe policies. For instance, in 2010, Arizona changed its life time limits from 60 months to 36 months and further down to 24 months in 2011. Additionally, at its TANF peak, Arizona's Maximum Aid amount for family of three was the lowest outside of the southern region. After the TANF peak in Arizona in 2009, unemployment rate had continued to rise another four months until March 2010.

Table 1: Number of severe (restrictive) policies across the states at each state's TANF peak month

\begin{tabular}{|c|c|c|c|c|c|c|c|c|c|c|c|c|c|}
\hline State & \begin{tabular}{|c|} 
LT or Temp \\
Limit
\end{tabular} & \begin{tabular}{|c|} 
Work \\
Required
\end{tabular} & Sanctions & $\begin{array}{c}\text { Restrictiveness } \\
\text { (out of 4) }\end{array}$ & $\begin{array}{l}\text { Rea } \\
\text { @ T }\end{array}$ & $\begin{array}{l}\text { I Max Aid } \\
\text { ANF Peak }\end{array}$ & State & \begin{tabular}{|c|} 
LT or Temp \\
Limit
\end{tabular} & \begin{tabular}{|c|} 
Work \\
Required
\end{tabular} & Sanctions & \begin{tabular}{|c|} 
Restrictiveness \\
(out of 4)
\end{tabular} & & $\begin{array}{l}\text { I Max Aid } \\
\text { ANF Peak }\end{array}$ \\
\hline Virginia & 1 & 1 & 1 & 3 & $\$$ & 305.20 & South Carolina & 1 & 0 & 0 & 1 & $\$$ & 258.74 \\
\hline \begin{tabular}{|l|} 
Alabama \\
\end{tabular} & 0 & 1 & 1 & 2 & $\$$ & 200.78 & Texas & 1 & 0 & 0 & 1 & $\$$ & 249.15 \\
\hline California & 1 & 1 & 0 & 2 & $\$$ & 612.69 & Utah & 1 & 0 & 0 & 1 & $\$$ & 479.88 \\
\hline Idaho & 1 & 0 & 1 & 2 & $\$$ & 282.93 & Washington & 0 & 1 & 0 & 1 & $\$$ & 536.00 \\
\hline lowa & 0 & 1 & 1 & 2 & $\$$ & 410.42 & West Virginia & 0 & 0 & 1 & 1 & $\$$ & 315.22 \\
\hline \begin{tabular}{|l} 
Michigan \\
\end{tabular} & 1 & 0 & 1 & 2 & $\$$ & 457.32 & Wisconsin & 0 & 1 & 0 & 1 & $\$$ & 579.38 \\
\hline \begin{tabular}{|l} 
Nevada \\
\end{tabular} & 1 & 0 & 1 & 2 & $\$$ & 357.68 & Arizona & 0 & 0 & 0 & 0 & $\$$ & 270.39 \\
\hline North Carolina & 1 & 1 & 0 & 2 & $\$$ & 263.59 & Colorado & 0 & 0 & 0 & 0 & $\$$ & 422.63 \\
\hline Ohio & 1 & 0 & 1 & 2 & $\$$ & 416.61 & District of Columbia & 0 & 0 & 0 & 0 & $\$$ & 391.53 \\
\hline Arkansas & 1 & 0 & 0 & 1 & $\$$ & 196.54 & Illinois & 0 & 0 & 0 & 0 & $\$$ & 395.19 \\
\hline Connecticut & 1 & 0 & 0 & 1 & $\$$ & 539.51 & Kansas & 0 & 0 & 0 & 0 & $\$$ & 398.76 \\
\hline \begin{tabular}{|l} 
Delaware \\
\end{tabular} & 1 & 0 & 0 & 1 & $\$$ & 387.09 & Kentucky & 0 & 0 & 0 & 0 & $\$$ & 242.54 \\
\hline Florida & 1 & 0 & 0 & 1 & $\$$ & 291.98 & Maine & 0 & 0 & 0 & 0 & $\$$ & 451.30 \\
\hline Louisiana & 1 & 0 & 0 & 1 & $\$$ & 223.32 & Maryland & 0 & 0 & 0 & 0 & $\$$ & 532.91 \\
\hline Massachusetts & 1 & 0 & 0 & 1 & $\$$ & 565.34 & Missouri & 0 & 0 & 0 & 0 & $\$$ & 270.72 \\
\hline Minnesota & 0 & 1 & 0 & 1 & $\$$ & 495.03 & New Hampshire & 0 & 0 & 0 & 0 & $\$$ & 647.95 \\
\hline Mississippi & 0 & 0 & 1 & 1 & $\$$ & 163.56 & Oklahoma & 0 & 0 & 0 & 0 & $\$$ & 281.32 \\
\hline Montana & 0 & 1 & 0 & 1 & $\$$ & 484.61 & Oregon & 0 & 0 & 0 & 0 & $\$$ & 462.88 \\
\hline Nebraska & 0 & 0 & 1 & 1 & $\$$ & 350.00 & Pennsylvania & 0 & 0 & 0 & 0 & $\$$ & 374.99 \\
\hline New Jersey & 0 & 1 & 0 & 1 & $\$$ & 391.17 & South Dakota & 0 & 0 & 0 & 0 & $\$$ & 512.03 \\
\hline New Mexico & 0 & 1 & 0 & 1 & $\$$ & 417.45 & Tennessee & 0 & 0 & 0 & 0 & $\$$ & 171.96 \\
\hline \multirow[t]{2}{*}{ New York } & 0 & 1 & 0 & 1 & $\$$ & 721.51 & Vermont & 0 & 0 & 0 & 0 & $\$$ & 585.46 \\
\hline & & & & & & & Wyoming & 0 & 0 & 0 & 0 & $\$$ & 550.70 \\
\hline
\end{tabular}

\subsection{An Index of TANF Responsiveness}

The responsiveness of TANF to the Great Recession is better understood when a state's relative TANF growth rate during the recession is calculated as a share of the average national growth of TANF caseloads. This figure is then divided by a state's relative percent growth in the 
number of unemployed as a share of the percentage growth in the average number of unemployed nationwide as shown in equation (a).

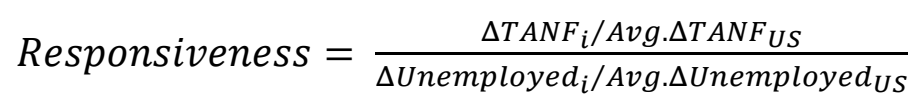

where,

$\triangle T A N F_{i}=\%$ change of TANF caseloads in state $i$ from minimum to maximum during own recession $A v g . \triangle T A N F_{U S}=$ Average $\%$ change of TANF caseloads in the U. S. from minimum to maximum $\Delta$ Unemployed $_{i}=\%$ change of Unemployed in state i during own recession

Avg. $\Delta$ Unemployed $_{U S}=$ Average $\%$ change of Unemployed in the U.S. during recession

It should be noted that for this calculation, we used the seasonally adjusted number of unemployed rather than the unemployment rate. We used the number of unemployed because the TANF caseload (the number of families) is a number and not a rate of families enrolled on public assistance. The outcome of such calculation captures the responsiveness of TANF to the recession in each state. While percent changes in the unemployment rate and number of unemployed in each state somewhat resemble one another, these were not identical. Changes in the seasonally adjusted unemployment rate tended to be greater than changes in the seasonally adjusted number of unemployed, partially because of the shrinkage in the labor force due to discouraged worker effects. Figure 1 shows spatial patterns in TANF responsiveness using this ratio index.

As demonstrated by Figure 1 below, states considered to be very responsive to the recession have higher ratios than their counterparts. In such states, the comparative growth rate of TANF caseload to the TANF national average growth rate is greater than the comparative growth in the number of unemployed to the national average increase. More responsive states would be considered more generous by some individuals. 


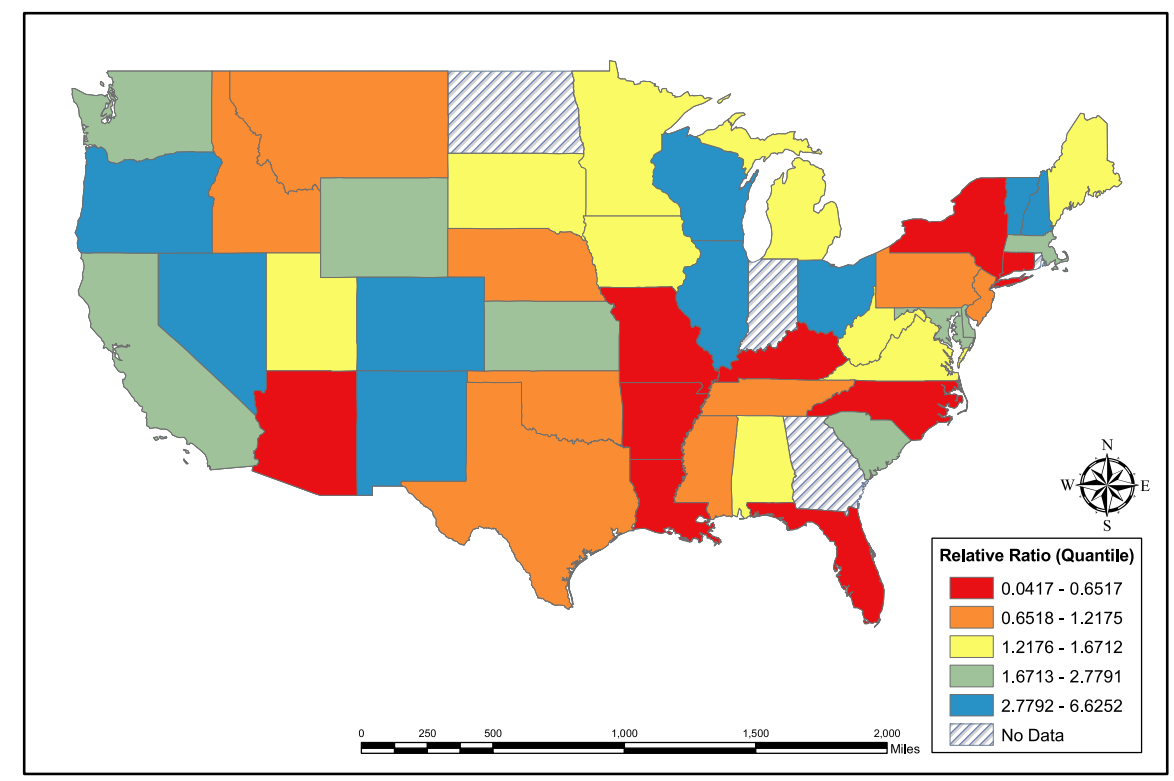

Figure 1. TANF Responsiveness Index (Ratio of Relative Change in TANF to Relative change in the Number of Unemployed)

With the exception of Arizona, all the other contiguous western states had ratios that exceeded one which means that the 10 other western states were found to be quite responsive to the recession. The most responsive states were Oregon, Colorado, New Mexico, and Nevada. In some cases, whereas some states had similar ratios of TANF responsiveness, their TANF caseloads grew at different rates. For example, whereas Montana and Idaho had similar level of responsiveness (1.217 and 1.175 , respectively), calculations show that the two states' TANF caseloads grew at different rates. Montana's TANF caseload grew at a much slower rate of $19.79 \%$ than Idaho's growth at 27.89 percent. Findings further reveal that Tennessee and Mississippi’s levels of TANF responsiveness are similar: 1.008 for Tennessee and 1.037 for Mississippi. Yet, TANF caseloads in Tennessee grew faster at $16.48 \%$ compared to Mississippi's growth at $8.08 \%$. As proven by these two cases, it is more accurate to develop a responsiveness index considering each state's labor market performance than simply examining TANF growth rate. 


\section{Methods}

\subsection{Exploratory Spatial Data Analysis}

Exploratory Spatial Data Analysis (ESDA) methods can be used to analyze the geographic varying patterns of a social indicator (e.g. TANF growth rate) [1]. ESDA is used to identify and statistically test the presence of spatial clusters and outliers as defined and explained in subsequent discussion. This spatial analytical tool can provide a basis for monitoring key social indicators at various geographic levels such as states or regions as is done in the present study.

ESDA is an extension of traditional exploratory data analysis (EDA) developed to detect spatial properties of data sets. In applying the ESDA, the first thing we did was to select a spatial weight matrix that describes the neighborhood structure among the spatial units of observation for a variable under consideration (e.g. TANF responsiveness ratio). Initially, we applied several neighborhood structures - one set based on contiguity and the other on distance and tested spatial autocorrelation under the various neighborhood structures. We used the Rook contiguity neighborhood structure for our statistical tests. This contiguity-based neighborhood structure identifies the states that share borders with a subject state. In order to determine whether there is a spatial autocorrelation at a global level, we tested for the overall (dis)similarity between the geographic location of states and changes in the TANF growth rates during the recession measured at a state-level among all the 45 observations (states).

The Moran's I statistics is used in order to detect the presence of global spatial autocorrelation as well as to test its statistical significance when applying a series of permutations for the contiguous states and D.C. To measure the global spatial autocorrelation, the strengths of spatial autocorrelation for all individual states are aggregated to develop a single composite statistical indicator, Moran's $I$, that determines the overall strength of spatial 
autocorrelation at global level. The Moran's $I$ values range from -1 to +1 . The closer the Moran's $I$ is to -1 , the greater the spatial dissimilarity. In contrast, the closer Moran's $I$ value is to +1 , the greater the spatial similarity. In the former case, spatial outliers are dominant, whereas spatial clusters are dominant in the latter case. When Moran's I statistic value gets closer to zero, the test fails to detect the statistical significance of spatial autocorrelation at a global level.

In order to test the spatial correlation at a local level we use a statistical test called Local Indicator of Spatial Association (LISA), applied for local indicators of spatial autocorrelation. This statistical technique tests the presence of spatial clusters or spatial outliers 45 times for each individual state's (dis)similarity between its own TANF growth change during the recession and the change in TANF growth rate of the state's geographic neighbors. Whereas in the case of Moran's I where we obtain only one statistical indicator, with LISA, we obtain 45 different LISA statistical indicators. Spatial clusters exist when there is positive spatial autocorrelation at the local level whereas spatial outliers can be detected when there is a negative spatial autocorrelation. Even without the presence of global spatial autocorrelation pattern, local patterns can be found to be statistically significant at a given significance level (for example, $p<$ $0.05)$.

It is critical to understand both global and local spatial autocorrelations for two reasons. First, under the presence of global spatial autocorrelation, the strength of local spatial clusters or spatial outliers might vary by region. In turn, it is also worthwhile testing at a local level. Second, even in the absence of global spatial autocorrelation, local level spatial regimes, both cluster and outliers may exist and this needs to be formally tested. In the present study, the two types of statistical tests (Moran's I for global and LISA for local levels) were performed for the 
unemployment rate, TANF growth rate, TANF responsiveness rate to rising unemployment and TANF maximum benefit levels for a family of three with no outside income.

\subsection{Moran's I and LISA Test Statistics}

In this section, both Moran's I equation and the LISA equations are presented. Moran's $I$ in equation (1) captures an existence of a global spatial autocorrelation for all the spatial jurisdictions in this study, the extent to which similar/dissimilar attribute values form spatial regime together among neighboring states in a spatial dataset. A spatial weight matrix $\left(w_{i j}\right)$ describes a neighborhood structure for the test, representing neighbors based on Rook contiguity as defined earlier. However, Moran's I statistics ignores local instabilities. As a complement, LISA (Local Indicator of Spatial Association) is a local index designed to measure spatial association for each spatial unit $i$ (a state in our study) with its own set of neighbors, $j$ (neighboring states that share boarders with subject state, $i$ ) as shown in equation (2). Moran's $I$ Statistics

$$
I=\frac{N}{\sum_{i=1}^{N} \sum_{j=1}^{N} w_{i j}}\left[\frac{\sum_{i=1}^{N} \sum_{j=1}^{N} w_{i j}\left(x_{i}-\bar{x}\right)\left(x_{j}-\bar{x}\right)}{\sum_{i}^{N}\left(x_{i}-\bar{x}\right)^{2}}\right]
$$

where, $\quad N=$ number of spatial units indexed by $i$ and $j$

$x=$ variable of interest

$\bar{x}=$ mean of $x$

$w_{i j}=$ an element of a spatial weight matrix

$$
I_{i}=\left[\frac{\left(x_{i}-\bar{x}\right) \sum_{j}^{N} w_{i j}\left(x_{j}-\bar{x}\right)}{\sum_{i}^{N}\left(x_{i}-\bar{x}\right)^{2}}\right]
$$

where, $\quad N=$ number of spatial units indexed by $i$ and $j$

$x=$ variable of interest

$\bar{x}=$ mean of $x$

$w_{i j}=$ an element of a spatial weight matrix 
The estimated LISA statistics from equation (2) are to test local spatial clusters and/or outliers for each individual spatial unit (state in our study). LISA maps only highlight the spatial units at a user-defined significance level and these are the core-spatial units for spatial clusters or spatial outliers. For High-High $(\mathrm{HH})$ spatial clusters, a core state is defined as a subject state that is tested and found to be statistically significant at $5 \%$ with its value higher for a particular indicator (e.g. unemployment rate) than the overall average and at the same time the subject state should be also surrounded by neighboring states with higher values for the indicator than the overall average. The same principle applies to Low-Low (LL) spatial clusters with lower than average values of an indicator for a subject state and among its neighboring states. In the case of spatial outliers, a core state is defined as the subject state that is tested and found to be statistically significant at $5 \%$ with its value higher (or lower) of an indicator than the overall average and also surrounded by its neighboring states with their values lower (or higher) than the overall average resulting in High-Low (HL) or Low-High (LH) outliers.

In order to formally test the existence of spatial associations in attribute values for the present study, a spatial analytical tool, GeoDa is employed to calculate Moran's I and LISA statistics [1]. GeoDa is an open source software program that serves as a tool for spatial data analysis, which is managed by The Center for Spatial Data Science at the University of Chicago. This tool analyzes spatial association, which is the (dis)similarity between geographic distribution of spatial units of observation (e.g., the states in our study) and their attribute values under consideration (e.g. TANF growth rate). 
In the following sections, we discuss the data used for the present study. Thereafter, we present findings from the Moran's $I$ and LISA tests which determine the spatial association or the (dis)similarity between geographic distribution of spatial units of observation and their attribute values under consideration. Based on how geographic neighbors are defined, the degree of spatial association may vary and a neighborhood weight matrix defines a neighborhood structure.

\section{Results}

\subsection{Growth in Unemployment Rate}

The Moran's I statistics was applied to formally test the spatial distribution of unemployment rate growth for each state, from its trough to its peak around the Great Recession of 2008. Calculations reveal an estimated Moran's I statistics value of 0.5382 and statistically significant at $1 \%$ level (pseudo p-value ${ }^{2}$ of 0.000010 ) based on the Rook Contiguity weight matrix. As a result, we reject the null hypothesis of random spatial distribution of the unemployment rate growth at $1 \%$ significant level. Consequently, we safely conclude that there exists global spatial association for the unemployment rate growth at state level during the Great Recession.

The LISA results in Figure 2 for the unemployment rate growth clearly shows spatial clusters among the 45 states included in this study. Six states in west form the core states in High-High (H-H) spatial clusters at 5\% significant level ( $\mathrm{HH}$ is shaded in red). These states are Oregon, California, Nevada, Arizona, Utah, and Idaho. These states show higher growth in unemployment rate change than the national average and are also surrounded by neighboring

\footnotetext{
2 “A computational approach based on permutation calculates a reference distribution for the statistic under the null hypothesis of spatial randomness by randomly permuting the observed values over the locations. The statistic is computed for each of these randomly reshuffled data sets, which yields a reference distribution.

This distribution is then used to calculate a so-called pseudo p-value." (Anselin, 2018)
} 
states with higher growth in unemployment rate changes than the national average based on 'Rook Contiguity' weight matrix. Four states form the core states for Low-Low (L-L) spatial clusters at 5\% significant level (LL, are shaded in blue). These states are Oklahoma, Missouri, Louisiana, and New Hampshire, with lower unemployment rate growth than the overall national average, surrounded by neighboring states with lower unemployment rate growth than the overall average. None of the 45 states is classified as a statistically significant spatial outlier at $5 \%$ significance level. Figure 2 shows a LISA map for the growth in unemployment rate variable.

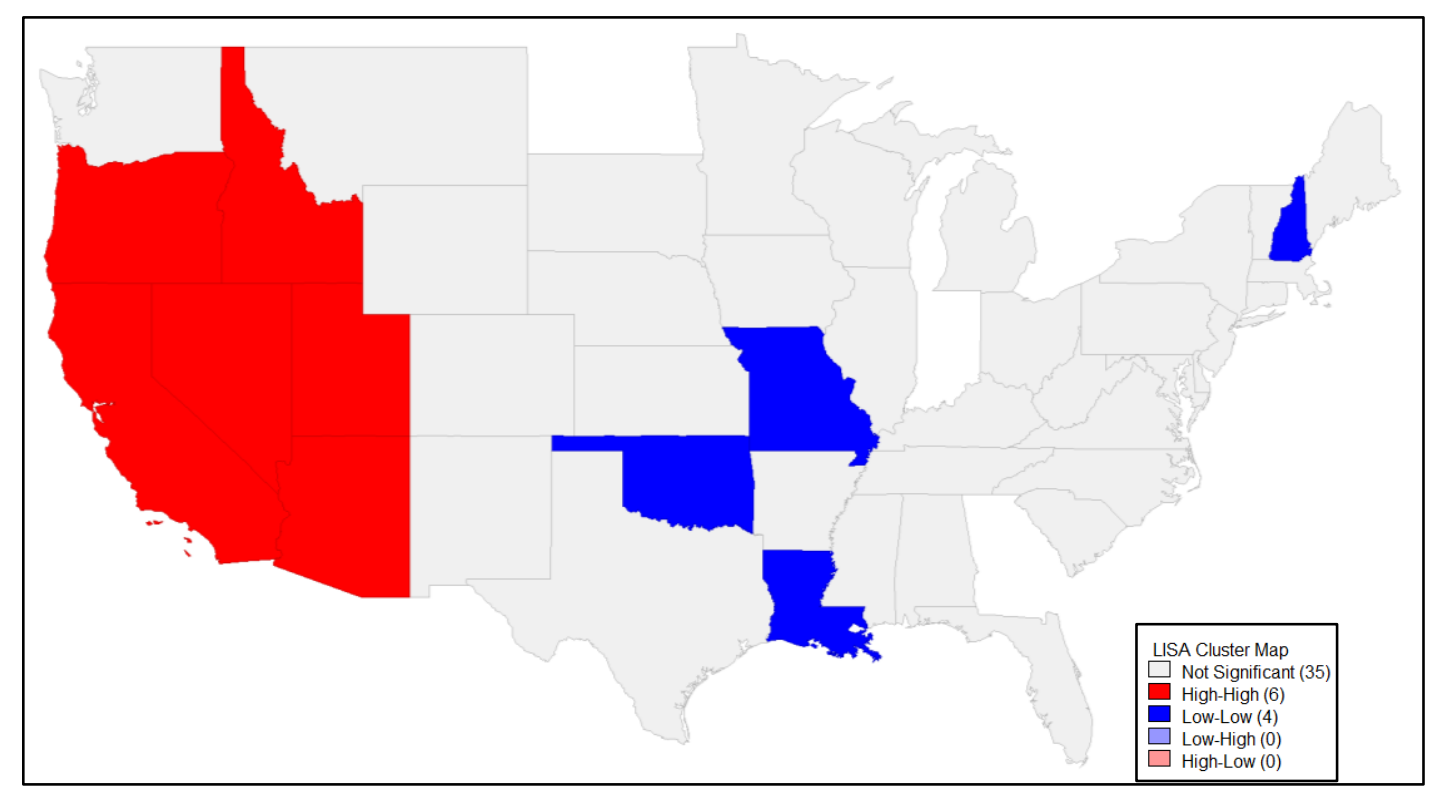

Figure 2. LISA Map for Unemployment Growth Rate

\subsection{Growth in TANF Caseload}

We tested the global spatial distribution of the TANF caseload change during each state's recession with Moran's I statistics. Estimated Moran's I statistics value of 0.1480 suggests a positive spatial autocorrelation, but it is not significant at $5 \%$ level with pseudo p-value of 0.059420. As a result, we cannot reject the null hypothesis of random spatial distribution of TANF 
change at 5\% significant level. Consequently, no global spatial association is detected at 5\% significance-level.

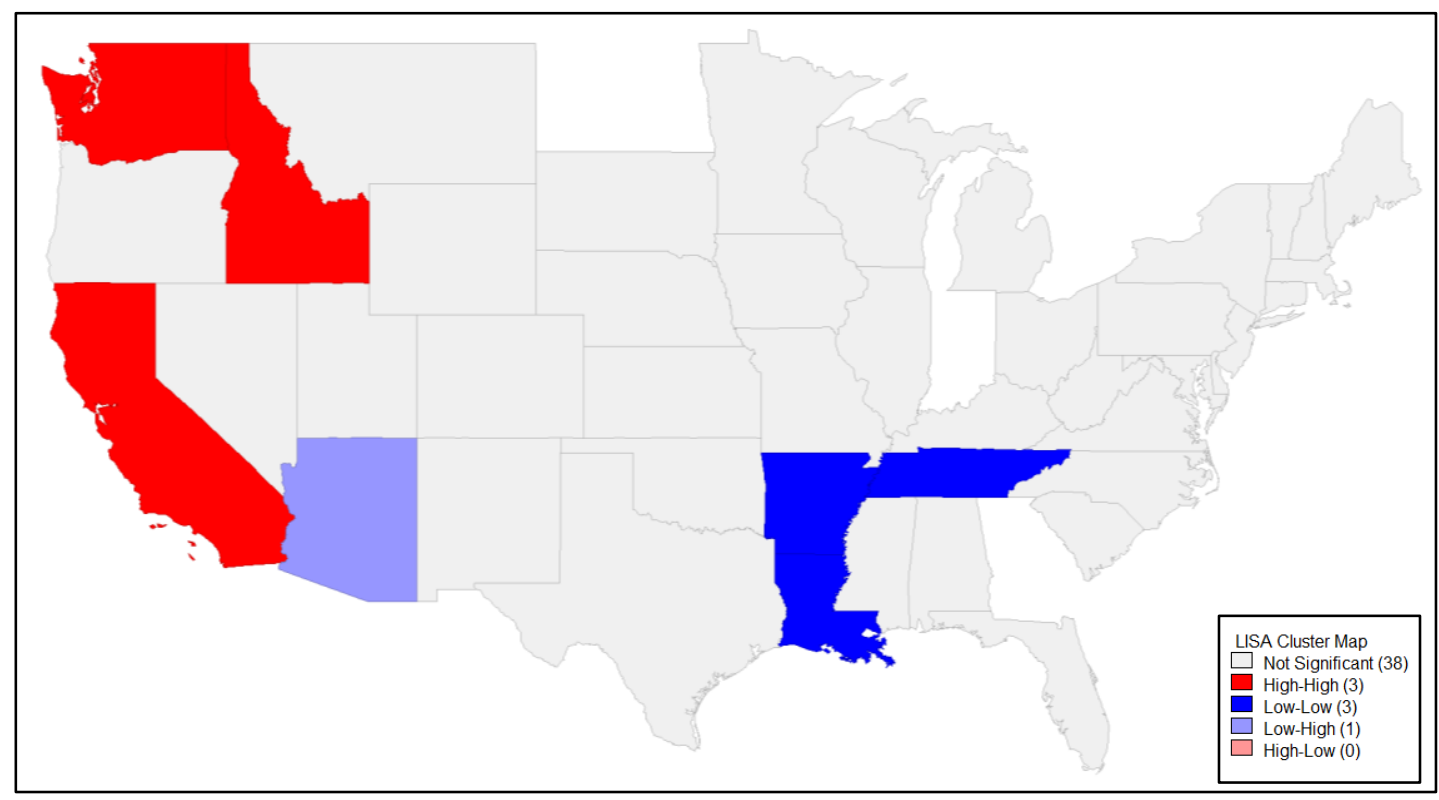

Figure 3. LISA Map for TANF Change in Each State's Recession

Figure 3, a LISA map, shows local spatial patterns for TANF changes among the 45 states included in this study. Six states form a spatial cluster at the 5\% significant level. Three states in the West serve as core states for High-High clusters (Washington, Idaho, and California) and the other three in the South, are the core states with Low-Low clusters (Arkansas, Louisiana, and Tennessee). The High-High clusters in the west suggest high TANF caseload changes and that they are also surrounded by neighboring states with high TANF growth, based on 'Rook contiguity neighbors' weight matrix. The latter spatial clusters are found in three core states which form LowLow spatial clusters with low TANF growth of the three states surrounded by their neighbors with low TANF growth rate. Arizona is the only state classified as a spatial outlier at $5 \%$ significant level because its TANF change is much lower than the overall average among the 45 spatial units where its three neighboring states had higher TANF change compared to the overall average. 


\subsection{TANF Responsiveness Index}

As described earlier, the responsiveness of TANF to the Great Recession is better captured when a state's relative TANF growth rate during the recession is calculated as a share of the average national growth of TANF caseloads. This figure is then divided by a state's relative percent growth in the number of unemployed as a share of the percent growth in the average number of unemployed nationwide as shown in equation (a).

The Estimated Moran's I statistics value of 0.0682 , indicates a potentially weak positive spatial autocorrelation for the spatial distribution of the TANF responsiveness to unemployment growth. However, based on the 'Rook Contiguity neighbors' weight matrix, pseudo p-value for global spatial autocorrelation is 0.183830 which results in accepting the null hypothesis of random spatial distribution of the responsiveness at 5\% significant level. Consequently, in this case, we conclude that in this case there is no global spatial association.

Yet, we were able to detect the existence of a few spatial clusters based on LISA (See Figure 4). Six states are found to be the core states of spatial clusters at 5\% significant level. The state of Washington, a core state, falls in High-High cluster ( $\mathrm{HH}$, shaded in red) primarily because the state has high TANF responsiveness and its neighboring states have high TANF responsiveness as well. States falling into a $\mathrm{HH}$ cluster can be defined as the states with a relatively higher TANF responsiveness rate than the overall average TANF responsiveness rate as well as being surrounded by neighboring states with higher than average TANF responsiveness rate. Washington State, a core state, has two neighboring states Oregon and Idaho which also witness high TANF responsiveness. However, Oregon and Idaho are not qualified as core states because their neighboring states, excluding Washington, are not $\mathrm{HH}$ states.

The other core five states, Arkansas, Louisiana, Mississippi, Tennessee, and Alabama, are 
states with Low-Low clusters in the South (LL, shaded in blue). The Low-Low cores states have a lower TANF responsiveness than overall average TANF responsiveness among the 45 sample states. Core states in this case are also surrounded by neighboring states with lower than average responsiveness. For example, Louisiana is a core state in the LL cluster with neighboring states of Arkansas, Texas and Mississippi, all of which have lower than average TANF responsiveness. However, while Texas has lower than average TANF responsiveness, it is not qualified as a core LL core state and is not shaded in blue because its neighboring state New Mexico has higher than average responsiveness. None of the states are classified as spatial outliers (either HL or LH) for the spatial distribution of TANF responsiveness.

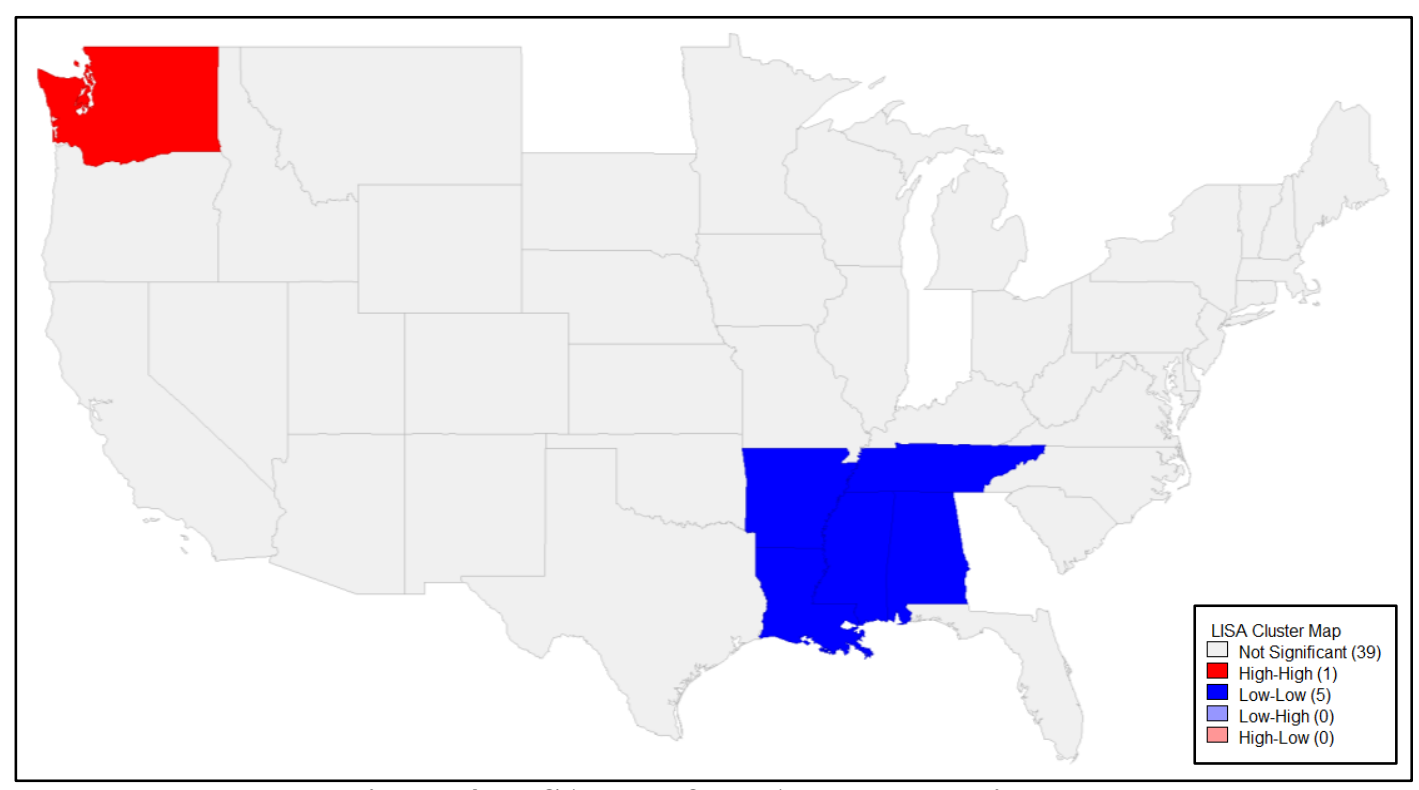

Figure 4. LISA Map for TANF Responsivenes 


\subsection{States' TANF Maximum Benefit Levels (maximum aid)}

Initially we analyzed spatial autocorrelations of several TANF policy variables, including TANF maximum aid, life time limits, sanctions, diversion payments or job search. Aside from TANF maximum aid, none of the other policy variables proved to have a statistically significant global spatial autocorrelation. Also, spatial patterns of these other policy variables at local levels were not quite strong. Therefore, we only present TANF maximum aid (payment levels) here that proved to have a statistically significant global spatial autocorrelation. We chose to apply spatial analyses to TANF maximum aid in real terms for a family of three (in 2007 US Dollars). This variable was captured at TANF's peak for each state. Studies have repeatedly shown that TANF maximum aid varied substantially among states, even when controlling for cost of living. During the Great Recession, several states cut their TANF benefit levels in nominal terms or simply let benefits erode with inflation. In contrast, there were some other states that chose to improve access to their programs by increasing their benefit levels or at least kept them up with inflation. This variable was chosen rather than other policy variables because the evidence is strong that this variable is a strong predictor of TANF enrollment.

We tested the global spatial autocorrelation for 'Maximum Aid Level at TANF Peak', measured in 2007 US Dollars. Our findings reveal that the estimated Moran's I statistics value was 0.6084 and that it is statistically significant at $1 \%$ level with pseudo p-value of 0.000010 based on the 'Rook Contiguity Neighbors' weight matrix. Consequently, we reject the null hypothesis of random spatial distribution of the maximum aid at TANF peak at $1 \%$ significant level. We are confident that there is a positive global spatial association.

Of all variables tested here for global or local associations, we found strong spatial association for maximum aid. The findings suggest that there is a strong presence of LL spatial cluster in 
Southern States and HH cluster in Northeastern States (see LISA Map, Figure 5). Nine southern states are found to be core states forming LL spatial clusters: Texas, Missouri, Arkansas, Louisiana, Mississippi, Alabama, Tennessee, Kentucky, and North Carolina.

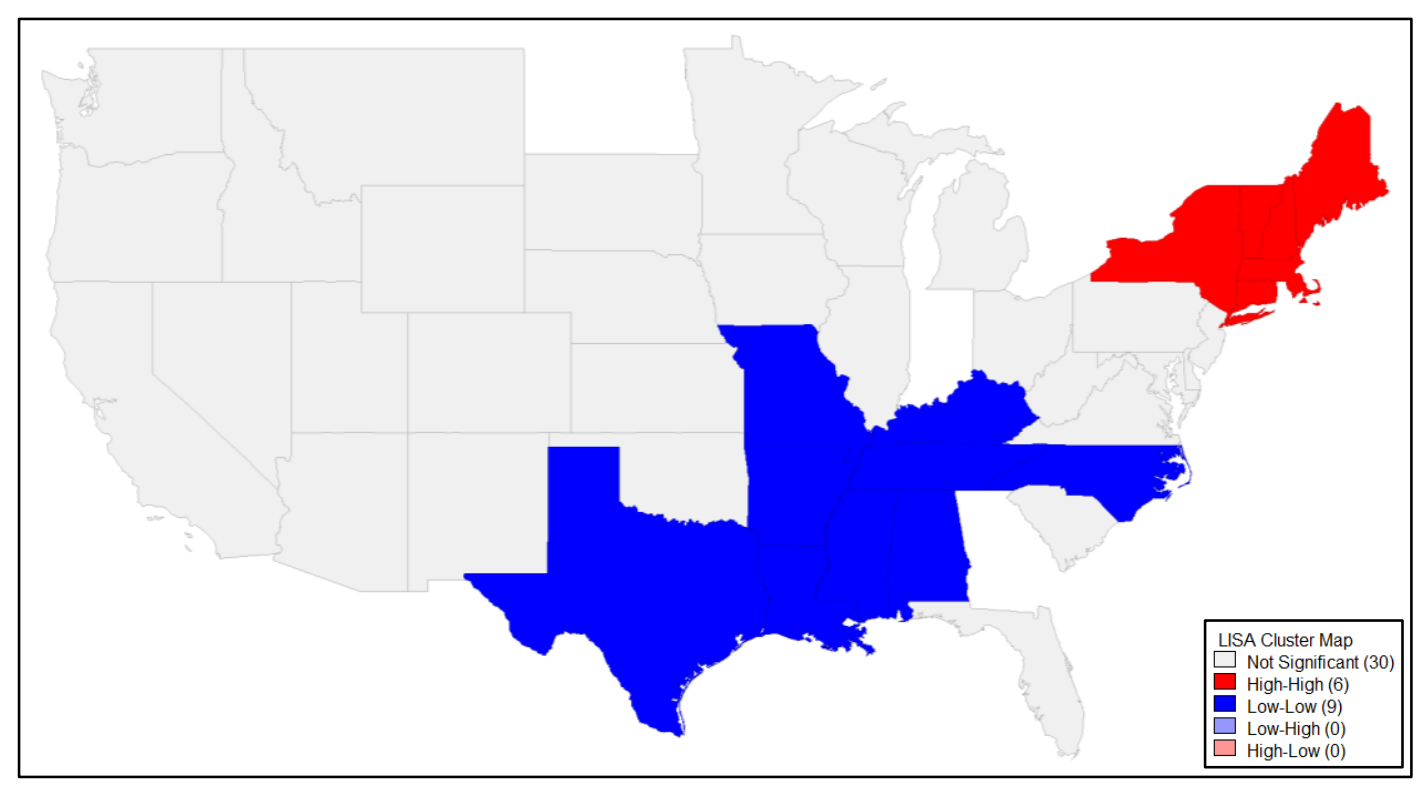

Figure 5. LISA Map for Maximum Aid Level at TANF Peak

As shown earlier, of these states, five states (Arkansas, Louisiana, Mississippi, Alabama, and Tennessee) also served as core states of Low-Low clusters with TANF responsiveness variable facing increasing numbers of unemployed. In a similar vein, six states in New England are found to be core states with High-High spatial clusters at 5\% significant level, including Maine, New Hampshire, Vermont, Massachusetts, Connecticut, and New York. These states show relatively higher maximum aid levels and are also surrounded by high maximum aid of neighboring states based on 'Rook contiguity neighbors' weight matrix. No spatial outliers were found among the 45 states. 


\section{Discussion}

In this paper, we argue that it is essential to analyze each state's 2008 recession rather than focus on the national official recession which lasted from 2007 to 2009. Consistent with some earlier findings, we found that the unemployment rate began rising before the onset of the national recession of December 2007 in 36 states and ended later than 2009.

Our study improves on most earlier studies that analyzed TANF during the 2008 recession in several additional ways. First, we developed a unique standardized TANF responsiveness index that more accurately captures the responsiveness of TANF program to the Great Recession. This standardized measure reveals that most of the western states were very responsive to the recession with ratios higher than one. In contrast, the findings suggest that states such as Texas and Arizona with ratios below 1, were unresponsive to the recession. Second, applying spatial statistical tools, we tested for spatial regimes. These statistical tools allowed us to determine the extent to which there have been regional and state-level variations regarding states' TANF benefit levels (maximum aid), unemployment rates, and TANF responsiveness to the recession. While we tested for spatial patterns for other policy variables, TANF benefit levels was the only policy variable that proved to be statistically significant at global level and confirmed the presence of spatial clusters. In the case of state's benefit levels, maximum aid, the fact that there is a strong presence of Low-Low spatial clusters in Southern States and High-High cluster in Northeastern States which is consistent with earlier findings conducted in non-recessionary periods [10]. Several low benefit neighboring states in the South have been known to have less of a financial commitment to poor families and children for several reasons including cost of living. In contrast, several neighboring high benefit states in the northeast continue to have financial commitment to the poor during the recession as they have prior to the recession. 
Our findings further show the presence of strong spatial clusters in the case of the unemployment rate which had global and local effects. For example, in the western region, 6 states were surrounded by neighbors that experienced high growths in unemployment rates (p $<.05)$. Yet, the fact that there were no strong spatial clusters in the case of TANF responsiveness to labor market performance only supports the notion that states do not necessarily pay attention to their neighbors' response to needy families during economic downturns.

The exploratory findings have implications for future federal actions and for state level collaboration. First, if the federal government wants states to become more responsive to the needs of poor families with children during a recession, it needs to measure responsiveness in the most accurate way possible. Using the index developed in the study is a good way to measure responsiveness. After this step, the federal government should find ways to financially help states that are responsive during recessions as well as incentivizing those who are not responsive to become more responsive to the needs of families with children in their states.

Regional and state-level collaborations among neighboring states should be encouraged by the federal government just as it encourages organizations to engage in collaboration when addressing local social problems. It may be effective to bring together neighboring states in order to strategically plan for solutions for rising demand for cash assistance. During the Great Recession, some of the western states may have felt more empowered by the federal government and formed neighborhood collaborations among the states that better addressed the needs of poor families with children. The states may have had a better chance of succeeding in helping families with children during the recession. 


\section{Author Contributions}

Dr Albert and Dr. Lim jointly conceptualized and implemented the research. Dr Lim had primary role in analyzing the data and results while Dr. Albert's led the writing of the manuscript.

\section{Funding}

The research was supported by School of Social Work at University of Nevada Las Vegas. The publication fees for this article were supported by the UNLV University Libraries Open Article Fund.

\section{Conflicts of Interest}

The authors declare no conflict of interest 


\section{References}

1. Anselin, L.; Sridharan, S.; Gholston, S. Using Exploratory Spatial Data Analysis to Leverage Social Indicator Databases: The Discovery of Interesting Patterns. Soc. Indicators Res. 2007, 82(2), 287-309; doi: 10.1007/s11205-006-9034-х.

2. Isard, W. Introduction to Regional Science; Prentice Hall: New York, NY, USA, 1975.

3. Haskins R.; Albert, V.; Howard, K. The responsiveness of the temporary assistance for needy families program during the Great Recession. 2016, Retrieved from: https://www.brookings.edu/wpcontent/uploads/2016/06/responsiveness_tanf_greatrecession haskins.pdf

4. Albert, V. State Policy Choices and Responsiveness of Temporary Assistance for Needy Families During the Great Recession. J. of Soc. Serv. Res. 2016, 42(4), 489-500; doi:10.1080/01488376.2016.1153564.

5. Albert. V.; Lim, J. (2018). Spatial Analyses of the Impact of Temporary Assistance for Needy Families on Child Neglect Caseloads During the Great Recession. J. of Soc. Serv. Res. 2018, 1-17; doi:10.1080/01488376.2018.1479341.

6. Pavetti, L.; Finch, I.; Schott, L. TANF emerging from the downturn a weaker safety net 2013 Retrieved from Center on Budget and Policy Priorities website: http://www.cbpp.org/ sites/default/files/atoms/files/3-1-13tanf.pdf.

7. Moffit, R.A. The Great Recession and Social Safety Net. Political and Social Science 2013, 650 issue: 1, page(s): 143-166.

8. Zedlewski, S. R.; Loprest, P. J.; Huber, E. What role is welfare playing in this period of high unemployment? (Fact Sheet 3) 2011, Retrieved from Urban institute website: 
https://www.urban.org/sites/default/files/publication/27456/412378-What-Role-is-WelfarePlaying-in-this-Period-of-High-Unemployment-.pdf.

9. Bitler, M.P.; Hoynes, H.W.; Jencks, C.; Meyer, B.D. The State of the Social Safety Net in the Post-Welfare Reform Era [with comments and discussions]. Brookings Papers on Economic Activity 2010,71-147. Retrieved from http:// www.jstor.org/stable/41012845

10. Albert, V.; Catlin S. Strategic interactions among the states: An in-depth look at the "race to the bottom." Social Work Research 2002, 26(4), 199-216.

DOI:10.1093/swr/26.4.199.

11. Kassabian, D.; Vericker, T.; Searle, D.; Murphy, M. Welfare rules databook: State TANF policies as of July 2010, 2011, Washington, DC: The Urban Institute. (See reference list for all references from urban institute welfare rules databook.) 